\title{
A morte como um fenômeno existencial a partir do conto literário O Muro e da filosofia de Jean-Paul Sartre
}

\section{Death as an existential phenomenon from the literary tale The Wall and the philosophy of Jean-Paul Sartre}

THIAGO SITONI GONÇALVES ${ }^{1}$

A morte, enquanto experiência assistida no mundo e temática que movimenta as minhas reflexões, apresentou-se para mim como acadêmico muito antes de ser um tópico especial ou de final capítulo dos livros teóricos sobre o desenvolvimento humano. Como escrevia Heidegger (2015) em Ser e Tempo, a morte é a certeza da vida e para além disso, ela desvelou-se minha aliada para movimentar a escrita do meu existir, para um capítulo mais autêntico e verdadeiro ao meu projeto de ser psicólogo e hoje, de ser escritor-leitor.

Como um recorte de um trabalho que fez parte do meu vir a ser hoje e prolongase nas vielas do futuro, este texto objetiva-se versar sobre o limiar da morte em interface com a literatura e a filosofia existencial de Sartre, pelo conto intitulado O Muro publicado em 1939, fragmento textual que chamou minha atenção para questionar sobre o fenômeno da morte da produção literária sartriana.

Para isso, em primeiro momento, é necessário desenvolver sobre a literatura produzida por esse filósofo. A literatura sartriana caracteriza-se como uma literatura da negatividade ou, como pontua Guimarães (2010), enquanto antiromance, pois, rompe com uma forma de escrever baseado em concepções idealistas de vida por meio de uma obra que nega a concepção de um romance natural e determinado, por uma escrita que reflete a história em toda sua imprecisão e ambiguidade. $\mathrm{O}$ termo negatividade é usado para manifestar a condição humana de ser-para-si em situação, temporal, histórica e marcado por contradições e conflitos. Nesse sentido, o antiromance surge como uma crítica ao mundo presente como algo inacabado, possível de transformação pela liberdade brotada (Silva, 2018) ontologicamente e, portanto, situada, e isso repercute nos personagens sartrianos por estarem inseridos em situações e confrontarem-se com seus dramas e dilemas existenciais.

Com base na delineação da literatura desenvolvida por Sartre, é de maior importância desenvolver acerca da trama literária que esse trabalho se alicerça. Este conto é articulado em uma atmosfera da Guerra Civil espanhola, no interior de uma prisão compartilhada com três personagens políticos. Em destaque, tem-se Pablo Ibbieta, o protagonista que norteará a construção da presente análise. Enclausurados, os prisioneiros recebem a sentença de morte iminente e a partir disso, o conto circunscreve as experiências existenciais da realidade humana a partir da consciência

\footnotetext{
- Psicólogo formado pela Universidade Paranaense (UNIPAR) e mestrando em Filosofia pela UNIOESTE. E-mail: thiagositonipsi@gmail.com
} 
determinada como facticidade. A partir da condenação à morte, Ibbieta entra em contato com alguns aspectos existenciais, a serem desenvolvidos neste tópico, tais como: a descoberta da temporalidade, da finitude da existência, da experiência do limite, da morte como facticidade e, também, a angústia existencial.

Para Sartre (2015 p. 670) o fenômeno da morte apresenta-se como insuperável, pois, ela é a extinção das possibilidades, o limite enquanto impossibilidade de concretização dos projetos do existente humano em seu fazer-se no mundo, isto é, "trata-se, pois, de um limite permanente de meus projetos, e, como tal, este limite é para ser assumido". A ocorrência da morte não se controla ou escolhe, isto é, faz parte das facticidades em existência. Ao desenvolver sobre a característica inelutável da morte, Sartre não se atém a concepções metafísicas ou religiosas que sejam capazes de amparar o mal estar do existente humano diante do fato que encerrará o para-si, totalizando-o em condição de ser-em-si, que significa algo encerrado, dado pela recordação e memória do outro.

A morte torna-se um dos maiores dramas humanos devido ao seu caráter de impedimento da própria existência, pois, como escreve Sartre (2015 p. 656), ela é o "[...] impedimento imprevisto, inesperado, que se deve levar em conta, conservando seu caráter específico de inesperado, mas que não podemos esperar, posto que se perde por si mesmo no indeterminado". Cada realidade humana em seu existir enfrenta a morte à sua maneira, visto que a subjetividade é construída na relação homem-mundo, em uma inevitável liberdade. Como pode-se levar em consideração a morte em existência? Como o existente humano enfrenta a morte?

Bueno Santos e Basseto (2018) fundamentam que, o fenômeno da morte pode ser visto como a consumação das possibilidades, na medida em que ao escolher um projeto, todos os outros aquém deste estão mortos, por mais que retornem ao presente, estarão em uma nova realidade e um novo contexto. Outro aspecto é o morrer, ou seja, um processo no qual a proximidade da morte consome a existência e a liberdade. Tais aspectos podem ser reconhecidos em um processo de adoecimento, retratado nas memórias de Simone de Beauvoir (2016 p. 138) ao deparar-se com a frágil condição de saúde de Sartre nos últimos dez anos de sua vida: "[...] O que é certo é que o drama de seus últimos anos é a consequência de toda a sua vida. É a ele que se podem aplicar as palavras de Rilke: 'Cada um carrega a sua morte em si, como a fruta seu caroço"'.

Diante da morte à espreita, cuja proximidade ceifa a existência gradativamente, pode-se articular que a realidade humana necessita fazer-se frente à essa limitação, desamparado de qualquer prisma ideológico além da própria responsabilidade, pois, a morte não dá contornos de sentido à existência. $O$ desamparo diz respeito ao desuso de justificativas metafísicas, ou seja, recursos advindos de uma natureza da alma ou da imortalidade de uma vida após a morte, envolvendo questões místico-religiosas. 
Com isso, a morte tem um caráter de absurdidade, pois, há desconhecimento acerca de seu acontecimento, o que por sua vez, impede uma suposta preparação. Dado a perspectiva de que o existente em sua liberdade traça suas ações à luz de seus projetos, o surgimento da morte torna-se o que Sartre expressa como absurdo, pois, "se sou espera de esperas de espera, e se, de súbito, o objeto de minha última espera e aquele que espera são suprimidos, a espera recebe retrospectivamente, o caráter de absurdidade" (SARTRE, 2015 p. 660-661).

Caxito (2018) sublinha o conceito de absurdo enquanto expressa um sentimento de estranhamento advindo da reflexão sobre alguma experiência vivida. Diante da reflexão sobre a morte, o sujeito apreende a realidade da contingência de sua existência, o fato de que essa terá um fim e que não tem necessidade de ser ou um sentido a oferecer amparo. $\mathrm{O}$ absurdo surge na medida em que há a reflexão sobre a minha morte. Essa expressão faz parte de uma secção da obra O Ser e o Nada (2015). Nesse capítulo, Sartre retoma a premissa de que o sentido do para-si é a temporalidade, isto é, uma sucessão de esperas que ocorre no existir. O vir-a-ser do para-si encerra quando suas esperas terminam com a nadificação de suas possibilidades, quando ele se torna um em-si. Essa nadificação é exatamente a morte, a consumação de todas as minhas possibilidades, e por isso, a morte é sentida pelo para-si como absurdo.

Outro aspecto é a morte do outro, que segundo Sartre (2015) é a vitória do outro sobre mim, visto que ele se torna o guardião das memórias que restaram no imaginário, nas quais não podem ser alteradas pelo existente humano, agora morto, encerrado. É o outro quem movimenta as memórias que restaram ou, por outro lado, é ele quem generaliza a morte, sendo mais uma na multidão. A perda de um ente querido, de relações e separações desvelam a morte a partir do interrompimento da relação intersubjetiva do homem no mundo com os outros e que a partir disso, deverá reconstruir-se a partir de novos possíveis.

O conto O Muro (1998) desenvolvido pelo filósofo, por outro lado, manifesta a morte a partir de sua característica determinada, desvelada pelo decreto de condenação, cuja certeza da descontinuidade da existência é vivenciada pelos personagens. Pablo Ibbieta é confinado devido a uma inquisição dos guardas a respeito de seu companheiro Gris, e nesse momento, anuncia-se que a condenação acontecerá no dia seguinte.

Ao receber a notícia de que será executado, o personagem não vê mais o sentido de suas condutas, dos motivos para não fazer denúncias aos guardas, o amor pela sua companheira e o desejo de viver, que eram inquestionáveis. Werle (2003) acrescenta que, neste conto, pela morte apresentar-se como sentença, Ibbieta recapitula toda a sua vida, levando a crer que ela nunca mais será a mesma, pois, perdera a ilusão de ser eterno. A descoberta da temporalidade acontece pelo fato de todas as experiências vividas por Ibbieta não retornarem, por ficarem confinadas ao 
passado, à uma recordação, irrepetível e que tornar-se-á impossível devido à proximidade de seu fim.

A ilusão de ser eterno é compreendida por Sartre (2015) ao caracterizar o homem como um livre mortal, que se projeta no mundo sem levar em consideração a morte em sua existência, devido ao fato dela retirar todo o significado fortificado da vida. Isso é retratado por Ibbieta ao enunciar que "havia passado o tempo todo a fazer castelos a eternidade" (SARTRE, 1998 p. 24). Tal afirmativa significa que o personagem vivencia um desencanto diante de todas as construções de valores positivos, as experiências vividas a partir da experiência do limite, pois, todas essas construções (ou castelos) desmoronam com fato de que não iriam retornar, devido a um limite que se aproxima e à finitude.

Ao referenciar a morte como um fenômeno que retira todo o significado da vida, Sartre não se refere a uma filosofia pessimista, cujo o sentido aproxima-se do niilismo, ou seja, de uma filosofia que defende uma existência sem qualquer contorno de sentido ou utilidade, aniquilando valores e significados. Sartre (2014) afirma que a existência possui sentido na medida em que o homem se faz nela, pelas suas ações no mundo, cuja liberdade e responsabilidade são aspectos cruciais de suas escolhas. A morte desmorona a construção de valores humanos frente à sua desconsideração pelo existente, e com sua certeza, desvela questionamentos frente às experiências fortificadas.

Outra questão apontada por Bueno, Santos e Basseto (2018) é a constatação da morte não ser a única experiência que os outros não podem fazer por mim, isto é, sentimentos, escolhas, também concernem à experiência humana em sua singularidade. Como Ibbieta estava enclausurado com mais dois políticos, a experiência da finitude é expressada no conto ao modo de cada personagem. A partir da ótica de Ibbieta, conforme a proximidade do momento da execução se aproxima, questiona-se como seria a execução (atropelamento ou fuzilamento), como seria a sensação das balas transpassando o seu corpo magro. Ele tem uma apreensão imaginativa de como seria a sua execução, como os outros olhariam para ele enquanto um corpo não mais aberto aos possíveis, mas, um corpo fisiológico. Em outras palavras, o personagem vivencia a sua morte em vida:

Aquilo não tinha sentido, não encontrava senão palavras, um vazio. Desde, porém, que começava a pensar em outra coisa, via canos de fuzis apontando para mim. Vivi talvez umas vinte vezes seguidas a minha execução; numa delas cheguei mesmo a pensar que o fuzilamento tinha ocorrido; devia ter dormido um minuto. [...] Naturalmente não podia pensar claramente na minha morte, mas eu a via por todos os lados, sobre as coisas, no jeito pelo qual as coisas tinham recuado e ser conservado a distância, discretamente, como pessoas que sussurram à cabeceira do moribundo (SARTRE, $1998 \mathrm{p}$. 23). 
Nesse ponto do desenvolvimento do conto, Sartre traça uma outra situação. Os guardas levam Ibbieta para uma outra sala, cuja intenção é fazer inquisições a respeito de Gris, e a partir disso, propor à Ibbieta a possibilidade de sua vida em troca pela delação, ou seja, escolher entre viver, contanto que oferecesse informações aos oficiais ou morrer diante de sua sentença. Neste momento, a liberdade e a angústia existencial estão expressivamente retratadas na construção da história.

Sartre (2014) manifesta a concepção de homem em liberdade, pelo fato de defender em sua filosofia existencial a ausência de determinismos, de todas as instâncias (biológicas, sociológicas, psicológicas, orgânicas, etc) anteriores à existência propriamente dita. Com isso, o homem se faz completamente desamparado de qualquer matriz criadora ou de quaisquer justificativas a priori, a não ser pela sua própria responsabilidade diante de suas escolhas à vista de seu projeto, dado à perspectiva de que o existir carece de sentido e a liberdade é o que subsidia o sentido do que é vivido.

É válido acrescentar que a liberdade não é uma elaboração fictícia, isto é, não tem a ver com o sentido empregado pelo senso comum ou de livre arbítrio, pela qual caracteriza a liberdade como sinônimo de fazer-se o que se quer. Como reforça Silva (2006), a liberdade é ontológica e tem seu contrapeso: a situação, e nesse caso, desenvolvido pelo conto, é uma situação extrema, defronte ao drama da morte.

Silva (2006) aponta que há uma ampliação do conceito de liberdade por Sartre retratar o existente humano não somente nos cafés ou na reclusão da intelectualidade, mas, por situar o homem na frente de um fuzil, prestes à morrer. A mesma liberdade de sua ontologia, de fazer-se no mundo, encontra-se também nessa situação da inquisição em que Ibbieta é invariavelmente livre. Nesse instante, o contexto histórico repercute no limite da situação em que o personagem está inserido.

Isso significa que, a Guerra Civil na Espanha, sua história pessoal, um muro que impede a sua fuga e seu drama ante à proximidade de sua execução, são fatores que caracterizam os limites de sua liberdade, pois, é esse pano de fundo que impõe Ibbieta a agir. Mesmo escolhendo em um plano pessoal, a sua eleição acontece no plano histórico (SILVA, 2006). Ou seja, a escolha existencial de Ibbieta é a decisão que implica em seu projeto em ser revolucionário político, baseado na sua ação em alistarse contra à um regime político fascista, autoritário na Espanha e após isso, ter a consequência de ser preso e ter vivido o drama da morte.

Ao ser preso, Silva (2006) reforça que a materialidade repercute na ação de Ibbieta, e é a partir desse ponto, que o plano histórico se encontra, isto é, a guerra, o aprisionamento, o fascismo e conflito social emergente em seu país, que delineiam a situação que se impõe enquanto contexto na qual a liberdade será exercida. A partir do momento em que é levado a outro espaço pelos guardas, tem-se uma abertura de 
possibilidade a respeito de seu fim ou da continuidade de sua existência, na qual o personagem é obrigado a escolher em uma dimensão ética.

Com isso, o personagem conta uma mentira aos guardas, ao mencionar o cemitério como esconderijo de Gris, dando, em primeiro momento, falsas pistas da sua localização. A angústia existencial encontra-se presente nesse momento, pois, ao estar situado na inquisição, Ibbieta deve escolher apesar de todas as experiências em cela, desprendido de amparo ou justificativas, principalmente, após reconhecer a sua ilusão de ser eterno e de que a sua morte é intransponível e, nesse contexto, determinada.

Bueno, Santos e Basseto (2018) retomam que a existência não pode ser definida somente com a relação do homem no mundo, mas, também pode ser circunscrita pela relação do homem com a sua morte, pois, enquanto facticidade, não se escolhe nascer, muito menos, não morrer, e no caso do conto previamente articulado, o personagem espera o seu próprio fim a partir do momento em que é enclausurado. Por uma fração de segundos, após ter experienciado todas as vicissitudes previamente desenvolvidas, ele tem a possibilidade de escolher entre a vida e a morte.

A dimensão ética, em Sartre (2014), expressa-se nessa questão, pois, na medida em que toda ação no mundo é singular e coletiva, a realidade humana torna-se responsável por si e por toda uma humanidade devido às marcas que deixará. Ibbieta necessita escolher: sua vida pela vida de Gris ou sua morte como destino traçado pelos guardas. Nisso, o personagem mente, entregando ao seu ver, pistas errôneas.

Mesmo assim, ao escolher uma resposta baseada em uma pseudo verdade, Ibbieta elege sua própria existência, mesmo com todos os desmoronamentos que isso implicou diante da certeza de sua morte e simultaneamente, expressa à humanidade que apesar da lealdade, da amizade e de todas as experiências advindas pela proximidade da morte, o personagem escolhe a própria vida. A revira-volta do conto acontece quando o truque de Ibbieta torna-se verdade. Os guardas o levam ao refeitório, e lá, recebe a notícia de que a falsa localização se tornou fato, pois, Gris havia se desentendido com um amigo que o auxiliou a refugiar-se da perseguição política. Com esse desentendimento, vai ao cemitério refugiar-se e, nesse momento, os guardas conseguem capturá-lo.

Nesse momento, a facticidade é outro elemento existencial presente na situação, que significa, o facto, aquilo que não pode ser controlado ou escolhido dado à perspectiva de que as situações são formadas por um conjunto de elementos, pelos quais o existente humano necessita enfrentar em face do seu projeto. Por sua vez, o conflito de Gris e sua fuga ao cemitério escapam à liberdade de Ibbieta, pela liberdade e projeto de Gris, ao retirar-se da casa em que estava escondido e ir ao cemitério, como uma alternativa para um novo esconderijo. 
Silva (2006) expressa que o princípio de liberdade está presente na extensa obra de Sartre e junto a ela, o conceito de situação fática. A ideia de situação é contrária a concepção de destino, visto que não se traça um percurso existencial determinado a priori ao existente humano, mas, a liberdade está sempre atrelada às facticidades, isto é, às coisas que estão aquém da escolha do existente humano. Ibbieta, ao manifestar sua resposta aos guardas, não poderia interferir com a sua ação mediante ao conflito de Gris.

O fato que escapa à sua ação, que não pôde contar é, por meio desse conflito, seu companheiro movimentar-se-ia para o lugar em que os guardas estavam à sua procura. Eis então, a característica literária sartriana de romper com uma forma de escrever baseado em concepções idealistas de vida por meio de uma obra que nega a concepção de um romance natural ou determinado a seguir um enredo lógico prevendo um final feliz, por uma escrita que manifesta a história em toda sua imprecisão e ambiguidade (GUIMARÃES, 2010).

\section{Referências}

BEAUVOIR, S. de. A cerimônia do adeus. Tradução de Rita Braga. Rio de Janeiro: Nova Fronteira, 2016.

BUENO, C. P. de; SANTOS, G. I. dos; BASSETO, A. D. “A morte sob a perspectiva fenomenológica existencial.” Diaphonía, v. 4 n. 2 p. 110-126. 2018 Disponível em: <http://erevista.unioeste.br/index.php/diaphonia/article/view/21310> Acesso em 17 out 2019.

CAXITO, F. A. “Absurdo e contingência em Camus e Sartre." ConTextura, v. 10 n. 13 p. 30-38. 2018. Disponível em:

<https://periodicos.ufmg.br/index.php/revistacontextura/article/view/3861> Acesso em 02 dez. 2019.

GUIMARÃES, F. M. Literatura e engajamento em Sartre: um estudo de Que é a Literatura. 2010. 108 f. Dissertação (Mestrado em Filosofia) - Pontifícia Universidade Católica de São Paulo, São Paulo, 2010.

HEIDEGGER, M. Ser e tempo. 10. ed. Tradução de Márcia Sá Cavalcante. Petrópolis, RJ: Vozes, 2015.

SARTRE, J-. P. O muro. Tradução de H. Alcântara Silveira. Rio de Janeiro: Nova Fronteira, 1998. p. 9-33.

SARTRE, J-. P. O existencialismo é um humanismo. Tradução de João Batista Kreuch.

Petrópolis, RJ: Vozes, 2014. p. 64.

SARTRE, J-. P. O ser e o nada: ensaio de ontologia fenomenológica. Tradução de Paulo Perdigão. Petrópolis, RJ: Vozes, 2015.

SILVA, C. A. F. "O brotar originário da liberdade: Sartre e a existência radical”, in ECOS Estudos Contemporâneos da Subjetividade, v. 8, p. 221-227, 2018. Disponível em:

http://www.periodicoshumanas.uff.br/ecos/article/view/2856.

SILVA, F. L. e. Ética e literatura em Sartre: ensaios introdutórios. São Paulo: UNESP, 2004 
A morte como um fenômeno existencial a partir do conto literário O Muro e da filosofia de Jean-Paul Sartre

SILVA, L. D. da. "Filosofia, literatura e dramaturgia: liberdade e situação em Sartre". Doispontos. v. 3 n. 2 p. 83-103, 2006. Disponível em:

<https://revistas.ufpr.br/doispontos/article/view/6506/4674> Acesso em 17 out. 2019

WERLE, M. A. “A angústia, o nada e a morte em Heidegger." Trans./Form./Ação. v. 26 n. 1 p. 97-113 Disponível em: <https://www.scielo.br/scielo.php?pid=So1o1-

31732003000100004\&script=sci_abstract\&tlng=pt $>$ Acesso em 16 fev de 2021.

Submissão: 16. 02. 2021 / Aceite: 30. 08. 2021 